\title{
Editorial: Entry-level Additive Manufacturing: the Next Frontier
}

\author{
Author: Eujin Pei \\ Correspondence email: eujinpei1@gmail.com \\ To cite this: Pei, E. (2015) Guest Editorial "Entry-level Additive Manufacturing: The Next Frontier". Rapid \\ Prototyping Journal 21(5) PP. $469-470$ \\ DOI: http://dx.doi.org/10.1108/RPJ-06-2015-0071
}

\begin{abstract}
About the author: Eujin is the Programme Director for the BSc Product Design and BSc Product Design Engineering programmes at Brunel University London. He was a Research Fellow at leading institutions including Loughborough University, Brunel University and the University of Southampton; and was a Visiting Scientist to Vaal University of Technology and Central University of Technology, Free State His professional design consultancy work includes those for BAE Systems Applied Intelligence, Motorola, Inc., LM Ericsson, Sennheiser $\mathrm{GmbH} \&$ Co. KG, and Rentokil Initial, of which some products are still manufactured and sold today. He is the Convenor for the International Organisation for Standardisation (ISO) TC261/WG4 group, leading Data Transfer and Design Standards for Additive Manufacturing, as well as holding various positions within ISO committee for Additive Manufacturing standards. Eujin is also a Chartered Technological Product Designer (CTPD) with Institution of Engineering Designers in the UK.
\end{abstract}

In 2010, under the direction of Dr lan Campbell from Loughborough University and Professor Deon de Beer at Vaal University of Technology, I undertook a series of experiments using the RapMan 3D Printer to understand the limitations of machine control and build characteristics (Pei et al., 2011). The conclusion was that the system had huge potential and it could democratise the entry-level rapid prototyping market. Fast forward five years, as I write this editorial, I have returned home from the three-dimensional (3D) Print Show in London. The crowd was largely composed of members of the public, including school children and mothers with push-prams. An interesting product was the ByFlow Focus printer that could fold into a suitcase with magnetically detachable extruders to swap between filaments, pastes and granulates. It was printing food and drew crowds. The talk by Adobe Systems, well known for the Photoshop software, showcased its latest iteration of Photoshop CC that could transform pictures into 3D textures and magically colourise 3D models. With the convergence of the Big Data with Social Media, the Internet of Things with Autonomous Systems and Cloud Manufacturing with Additive Manufacturing (AM), I am looking forward to an exciting, technology-fuelled future (Figure 1).

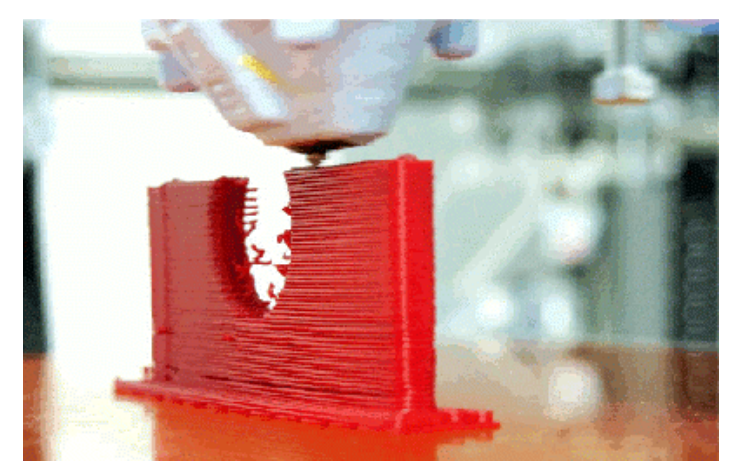

Figure 1 - Using the RapMan 3D Printer in 2009 as one of the few entry-Level 3D Printers available at that time was a very rewarding experience 
This special issue is composed of articles that examine the impact of entry-level additive manufacturing (ELAM), reminding us that AM research should not be limited to sophisticated systems. This issue contains 12 specifically chosen papers. "The Design and Assessment of a 3D Printing Vending Machine" is a good example of providing 3D printing services to empower student learning. "Multidisciplinary Approach in Engineering Education: Learning with Additive Manufacturing and Reverse Engineering" and the "Impact of Additive Manufacturing on Engineering Education - Evidence from Italy" showed evidence of the benefits of AM in Engineering education. General applications are covered in "What Are You Printing? - Ambivalent Emancipation by 3D Printing" where case studies from a FabLab are investigated, showing the importance of engaging the public from being bystanders to users of technology. "+TUO Project: Low Cost 3D Printers as Helpful Tools for Small Communities with Rheumatic Diseases" discusses co-designing with patients to produce prototypes, and "An Assessment of Implementation of Entry-Level 3D Printers from the Perspective of Small Businesses" provides examples of SMEs using 3D Printers for testing and discusses the advantages and disadvantages of small-scale production facilities. Features of hardware control are discussed in "Low-Cost Closed-Loop Control of a 3D Printer Gantry" where the controller can capture and compensate the dynamics of the motor and belt drive to improve the print quality. The subject of benchmarking the printers and the quality of printed parts is discussed in the "Evaluation of Dimensional Accuracy and Material Properties of the MakerBot 3D Desktop Printer" and "The Impact of Process Parameters on Mechanical Properties of Parts Fabricated in PLA with an Open-source 3-D Printer" quantifies the ultimate tensile strength and the nominal strain at break of PLA parts. The "Multi-Material Additive and Subtractive Prosumer Digital Fabrication with a Free and Open-source Convertible Delta RepRap 3-D Printer" suggests novel modifications to extend the capabilities of a conventional printer for fixed tool applications. "Experimental Desktop 3D Printing Using Dual Extrusion and Water-Soluble Polyvinyl Alcohol" discusses the challenges of multiple extrusion systems and explores techniques to dissolve PVA as a support material. I have written papers on 4D printing (Pei, 2014a, 2014b), where scientists claim that functionally graded parts have the potential to transform static objects into those that can evolve over time. The "Additive Manufacturing of Mechanochromic Polycaprolactone on Entry-Level Systems" paper opens up the field of smart materials for ELAM. Finally, "Direct 3D Printing of Polymers onto Textiles: Experimental Studies and Applications" pushes the boundaries of existing work by assessing the viability of printing directly onto textiles with implications for wearable technology.

So what can we expect of the future? I believe we will see greater affordability of entry-level 3D printers and as teaching of computer aided design (CAD) and AM becomes prevalent in schools, the new generation of makers will be more confident and creative. We will see specialised Fablabs catering for specific needs, such as crafts or even mobile repair services. Despite these hopes, we have to be aware of the "Singer problem", a term from Joris Peels about the hype of home appliances, such as sewing machines and bread makers that have failed to turn us into makers. Moving on from this special issue of the Rapid Prototyping Journal, I thank our Editor-in-Chief, Dr lan Campbell, for providing me with this opportunity to serve as a Guest Editor. My thanks also go to the Publisher, Daniel Jopling, and his team for their valuable support. Finally, I am grateful to our reviewers for their considerable effort to provide high-quality feedback for this special issue.

Eujin Pei 


\section{References}

1. Pei, E. (2014a), "4D printing: dawn of an emerging technology cycle", Assembly Automation, Vol. 34 No. 4, pp. 310-314.

2. Pei, E. (2014b), “4D printing - revolution or fad?", Assembly Automation, Vol. 34 No. 2, pp. 123-127.

3. Pei, E., Campbell, R.I. and de Beer, D. (2011), "Entry-level RP machines: how well can they cope with geometric complexity?", Assembly Automation, Vol. 31 No. 2, pp. 153-160. 